\title{
Allergic Rhinitis and its Impact on Asthma (ARIA) guidelines-2016 revision
}

Jan L. Brożek, MD, PhD, ${ }^{a, b}$ Jean Bousquet, MD, PhD, ${ }^{c}$ loana Agache, MD, PhD, ${ }^{d}$ Arnav Agarwal, BHSc, ${ }^{a, e}$ Claus Bachert, MD, PhD, ${ }^{f}$ Sinthia Bosnic-Anticevich, BPharm, PhD, ${ }^{9}$ Romina Brignardello-Petersen, DDS, MSc, PhD, ${ }^{a}$ G. Walter Canonica, MD, ${ }^{\text {h }}$ Thomas Casale, MD, ${ }^{i}$ Niels H. Chavannes, MD, PhD, jaime Correia de Sousa, MD, PhD, ${ }^{k}$

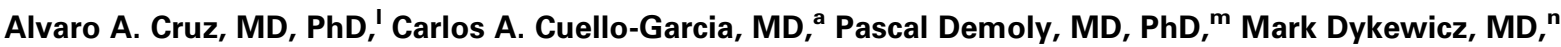
Itziar Etxeandia-Ikobaltzeta, PhD, ${ }^{a}{ }^{\text {,o }}$ Ivan D. Florez, MD, MSc, ${ }^{\text {a,p }}$ Wytske Fokkens, MD, PhD, ${ }^{\mathrm{q}}$ Joao Fonseca, MD, PhD, Peter W. Hellings, MD, PhD, ${ }^{\text {s }}$ Ludger Klimek, MD, PhD, ${ }^{\mathrm{t}}$ Sergio Kowalski, MD, ${ }^{2}$ Piotr Kuna, MD, PhD, Kaja-Triin Laisaar, MD, MPH, ${ }^{v}$ Désirée E. Larenas-Linnemann, MD, ${ }^{w}$ Karin C. Lødrup Carlsen, MD, PhD, ${ }^{x}$

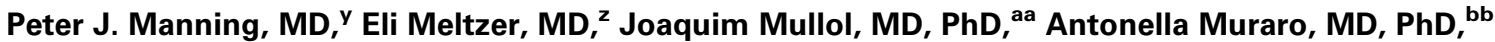

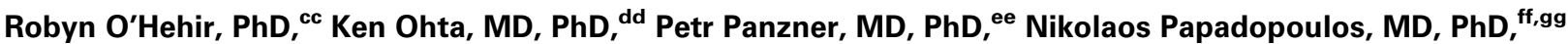
Hae-Sim Park, MD, PhD, ${ }^{\text {hh }}$ Gianni Passalacqua, MD, ${ }^{\text {ii }}$ Ruby Pawankar, MD, PhD, ij David Price, MD, ${ }^{\text {kk }}$ John J. Riva, DC, MSc, a,ll Yetiani Roldán, MD, ${ }^{a}$ Dermot Ryan, MD, ${ }^{\text {mm }}$ Behnam Sadeghirad, PharmD, MPH, ${ }^{\text {nn }}$ Boleslaw Samolinski, MD, PhD, ${ }^{\text {oo }}$ Peter Schmid-Grendelmeier, MD, ${ }^{\text {pp }}$ Aziz Sheikh, MD, MSc, ${ }^{\text {qq }}$ Alkis Togias, MD, ${ }^{\text {rr }}$ Antonio Valero, MD, PhD, ${ }^{\text {ss }}$ Arunas Valiulis, MD, PhD, ${ }^{\text {tt }}$ Erkka Valovirta, MD, PhD, ${ }^{\text {uu }}$ Matthew Ventresca, MSc, ${ }^{\text {a }}$ Dana Wallace, MD, ${ }^{\text {vv }}$ Susan Waserman, MD, MSc, ${ }^{b}$ Magnus Wickman, MD, ${ }^{\text {ww }}$ Wojtek Wiercioch, MSc, ${ }^{a}$ Juan José Yepes-Nuñez, MD, MSc, ${ }^{\text {a,xx }}$ Luo Zhang, MD, ${ }^{\text {yy }}$ Yuan Zhang, MPH, ${ }^{\text {a }}$ Mihaela Zidarn, MD, MSc, ${ }^{2 z}$ Torsten Zuberbier, MD, ${ }^{\text {aaa }}$ and Holger J. Schünemann, MD, PhD, MSc ${ }^{\text {a,bbb }}$

Hamilton and Toronto Ontario, Canada; Montpellier and Paris, France; Brasov, Romania; Ghent and Brussels, Belgium; Sydney and Melbourne, Australia; Milan, Padua, and Genoa, Italy; Tampa and Fort Lauderdale, Fla; Leiden and Amsterdam, The Netherlands; Braga/Guimarães and Porto, Portugal; Salvador, Brazil; Vitoria-Gasteiz and Barcelona, Spain; St Louis, Mo; Medellin, Colombia; Wiesbaden and Berlin, Germany; Lodz, Poland, Tartu, Estonia; Mexico City, Mexico; Oslo, Norway; Dublin, Ireland; San Diego, Calif; Tokyo, Japan; Prague, Czech Republic; Athens, Greece; Manchester, Aberdeen, and Edinburgh, United Kingdom; Suwon, Korea; Kerman, Iran; Warsaw, Poland; Davos, Switzerland; Bethesda, Md; Vilnius, Lithuania; Turku, Finland; Stockholm, Sweden; Beijing, China; and Golnik, Slovenia

From ${ }^{a}$ the Department of Clinical Epidemiology and Biostatistics, and ${ }^{b}$ the Division of Clinical Immunology and Allergy, Department of Medicine, McMaster University, Hamilton; ${ }^{c}$ University Hospital, Montpellier; ${ }^{\mathrm{d}}$ the Faculty of Medicine, Transylvania University, Brasov; ${ }^{\mathrm{e}}$ the School of Medicine, University of Toronto; ${ }^{\mathrm{f}}$ the Upper Airways Research Laboratory, Ghent University Hospital; ${ }^{\text {g }}$ the Woolcock Institute, University of Sydney; hthe Asthma \& Allergy Clinic, Humanitas University, Rozzano, Milan; ithe Division of Allergy and Immunology, University of South Florida, Tampa; ${ }^{j}$ the Department of Public Health and Primary Care, Leiden University Medical Center; ${ }^{k}$ the Life and Health Sciences Research Institute (ICVS), School of Health Sciences, University of Minho, Braga, and ICVS/3B's-PT Government Associate Laboratory,

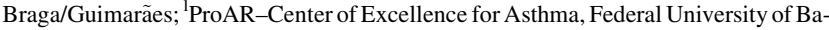
hia, Salvador; ${ }^{\mathrm{m}}$ University Hospital of Montpellier, Montpellier, and Sorbonne Universités, UPMC Paris 06, UMR-S 1136, IPLESP, Equipe EPAR, Paris; ${ }^{\mathrm{n}}$ the Section of Allergy and Immunology, Department of Internal Medicine, Saint Louis University School of Medicine; ${ }^{\circ}$ Dirección de Investigación e Innovación Sanitaria, Departamento de Salud, Gobierno Vasco-Eusko Jaurlaritza, Vitoria-Gasteiz; ${ }^{\mathrm{p}}$ the Department of Pediatrics, University of Antioquia, Medellin; ${ }^{\mathrm{q}}$ the Department of Otorhinolaryngology, Academic Medical Centre, Amsterdam; ${ }^{\mathrm{r}}$ CINTESIS-Center for Health Technology and Services Research, Faculdade de Medicina, Universidade do Porto \& Allergy,

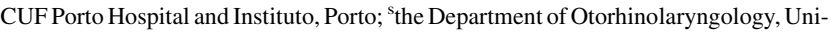
versity Hospitals Leuven, and the Department of Otorhinolaryngology, Academic Medical Center (AMC), Amsterdam; 'the Center of Rhinology and Allergology, Wiesbaden; "the Division of Internal Medicine Asthma and Allergy, Faculty of Medicine, Medical University of Lodz; 'the Institute of Family Medicine and Public Health, University of Tartu; ${ }^{\mathrm{w}}$ Hospital Médica Sur, Mexico City; ${ }^{\mathrm{x}}$ the Department of Paediatrics, Oslo University Hospital, University of Oslo; ${ }^{y}$ the Department of Medicine, Royal Col-

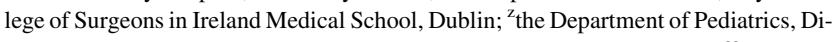
vision of Allergy \& Immunology, University of California, San Diego; ${ }^{\text {aa } U n i t a t ~ d e ~}$ Rinologia i Clínica de l'Olfacte, Servei d'ORL, Hospital Clínic, Clinical \& Experimental Respiratory Immunoallergy, IDIBAPS, Barcelona; ${ }^{\text {bb }}$ the Department of Women and Child Health \& Food Allergy Referral Centre Veneto Region, University of Padua; ${ }^{\mathrm{cc}}$ Alfred Hospital and Monash University, Melbourne; ${ }^{\mathrm{dd}}$ National Hospital
Organization Tokyo National Hospital, Kiyose-city, Tokyo; ${ }^{\text {ee }}$ the Department of Immunology and Allergology, Faculty of Medicine in Pilsen, Charles University in Prague; ${ }^{\mathrm{ff}}$ the Allergy Department, 2nd Pediatric Clinic, University of Athens; ${ }^{\mathrm{gg}}$ the Division of Infection, Immunity \& Respiratory Medicine, University of Manchester; ${ }^{\text {hh }}$ the Department of Allergy and Rheumatology, Ajou University School of Medicine, Suwon; ${ }^{i} \mathrm{Al}-$ lergy and Respiratory Diseases, IRCCS San Martino, IST, University of Genoa; ${ }^{\mathrm{jj}}$ the Department of Pediatrics, Nippon Medical School, Tokyo; ${ }^{\mathrm{k}}$ the University of Aberdeen; ${ }^{\text {Il }}$ the Department of Family Medicine, McMaster University, Hamilton; ${ }^{\mathrm{mm}}$ the Allergy and Respiratory Research Group, Usher Institute of Population Health Sciences and Informatics, University of Edinburgh; ${ }^{n n}$ the HIV/STI Surveillance Research Center, and World Health Organization Collaborating Center for HIV Surveillance, Institute for Futures Studies in Health, Kerman University of Medical Sciences; ${ }^{\circ}$ the Department of Prevention of Environmental Hazards and Allergology, Medical University of Warsaw; ${ }^{\text {pP }}$ the Allergy Unit, Department of Dermatology, University Hospital of Zürich and Christine Kühne Center for Allergy Research and Education CK-CARE, Davos; ${ }^{\mathrm{qq}}$ Asthma UK Centre for Applied Research, Usher Institute of Population Health Sciences and Informatics, University of Edinburgh; ${ }^{\text {rr }}$ Asthma and Inflammation, National Institute of Allergy and Infectious Diseases, National Institutes of Health, Bethesda; ${ }^{\text {ss }}$ the Department of Pneumology and Allergy, Immunoallèrgia Respiratòria Clínica I Experimental (IDIBAPS), Centro de Investigaciones Biomédicas en Red de Enfermedades Respiratorias (CIBERES), Barcelona; "tVilnius University Clinic of Children's Diseases and Public Health Institute, Vilnius, and the European Academy of Paediatrics (EAP/UEMS-SP), Brussels; ${ }^{\text {uu }}$ the Department of Lung Diseases and Clinical Immunology, University of Turku and Allergy Clinic Terveystalo Turku; ${ }^{\mathrm{vv}}$ Nova Southeastern University, Fort Lauderdale; ${ }^{\mathrm{ww}}$ the Department of Pediatrics, Sachs' Children's Hospital, South General Hospital and Institute of Environmental Medicine, Karolinska Institutet, Stockholm; ${ }^{\mathrm{xx}}$ the School of Medicine, University of Antioquia, Medellín; ${ }^{y y}$ the Department of Otolaryngology Head and Neck Surgery, Beijing TongRen Hospital and Beijing Institute of Otolaryngology; ${ }^{\mathrm{zz}}$ University Clinic of Pulmonary and Allergic Diseases Golnik; ${ }^{\text {aaa }}$ the Department of Dermatology and Allergy, Charité-Universitätsmedizin Berlin; and ${ }^{\text {bbb }}$ the Division of General Internal Medicine, Department of Medicine, McMaster University. 


\author{
Background: Allergic rhinitis (AR) affects $10 \%$ to $40 \%$ of the \\ population. It reduces quality of life and school and work \\ performance and is a frequent reason for office visits in general \\ practice. Medical costs are large, but avoidable costs associated \\ with lost work productivity are even larger than those incurred
}

by asthma. New evidence has accumulated since the last revision of the Allergic Rhinitis and its Impact on Asthma (ARIA) guidelines in 2010, prompting its update. Objective: We sought to provide a targeted update of the ARIA guidelines.
Disclosure of potential conflict of interest: J. L. Brożek has received support for the development of systematic reviews in these guidelines from the ARIA Initiative. J. Bousquet has received personal fees from Almirall, Meda, Merck, MSD, Novartis, Sanofi-Aventis, Takeda, Teva, Uriach, Chiesi, GlaxoSmithKline, and Menarini. S. Bosnic-Anticevich is on the advisory board for TEVA; has consultant arrangements with MEDA and GlaxoSmithKline; has received grants from TEVA; has received payment for lectures from TEVA, GlaxoSmithKline, and AstraZeneca; has received payment for manuscript preparation from MEDA; and has received payment for development of educational presentations from GlaxoSmithKline. T. Casale is the executive vice president of the American Academy of Allergy, Asthma \& Immunology. J. Correia de Sousa has board memberships with Boehringer Ingelheim and Novartis, has received payment for lectures from Boehringer Ingelheim, and has received payment for development of educational presentations from Boehringer Ingelheim. A. A. Cruz has board memberships with Novartis, Boehringer Ingelheim, AstraZeneca, MEDA Pharma, and GlaxoSmithKline; has consultant arrangements with Boehringer Ingelheim; has provided expert testimony for Boehringer Ingelheim; has received grants from GlaxoSmithKline; and has received payment for lectures from Eurofarma, Chiesi, MEDA Pharma, and Hypermarcas-Ache. C. A. Cuello-Garcia has consultant arrangements with and has received payment for manuscript preparation and travel support from the World Allergy Organization. P. Demoly has received consulting fees from ALK-Abelló, Stallergenes Greer, Thermo Fisher Scientific, MEDA, Chiesi, and Ysslab and has received grants from AstraZeneca. M. Dykewicz has consultant arrangements with Alcon and Merck and is the Workgroup Char for the Rhinitis Practice Parameter Update of the American Academy of Allergy, Asthma \& Immunology/American College of Allergy, Asthma \& Immunology ACAAI Joint Task Force on Practice Parameters. I. Etxeandia-Ikobaltzeta has received a consulting fee or honorarium from MacGRADE Centre. W. Fokkens has consultant arrangements with MEDA/Mylan; has received grants from MEDA/Mylan, GlaxoSmithKline, MAPI S.A.S.-RWE, Allakos, and Sanofi; and has received payment for lectures from MEDA/Mylan. J. Fonseca has received payment for lectures from A. Menarini and FAES Farma (Lab. Vitória) and has received payment for development of educational presentations and travel support from A. Menarini. L. Klimek has board memberships with MEDA and Novartis; has consultant arrangments with ALK-Abelló, MEDA, Novartis, Allergopharma, Bionorica, Boehringer Ingelheim, GlaxoSmithKline, and Lofarma; has received grants from ALK-Abelló, Novartis, Allergopharma, Bionorica, GlaxoSmithKline, Lofarma, Biomay, HAL, LETI, Roxall, and Bencard; has received payment for lectures from ALK-Abelló, MEDA, Novartis, Allergopharma, Bionorica, Boehringer Ingelheim, GlaxoSmithKline, and Lofarma; has received payment for manuscript preparation from Bionorica; and has received payment for performing a clinical trial from ALK-Abelló. S. Kowalski is employed by Universidade Federal do Parana. P. Kuna has board memberships with Boehringer Ingelheim, ALK-Abelló, FAES, Sandoz, Teva, Polpharma, Novartis, Allergopharma, and Celon Pharma; received payment for lectures from Adamed, Allergopharma, ALK-Abelló, AstraZeneca, Bayer, Berlin Chemie, Boehringer Ingelheim, Chiesi, Faes, HAL Allergy, Lekam, Novartis, Polharma, Pfizer, Sandoz, and Teva; and has received travel support from Novartis, Berlin Chemie, and Boehringer Ingelheim. D. E Larenas-Linnemann has consultant arrangements with MEDA, Boehringer Ingelheim, and Mitfarma; has received grants from AstraZeneca, TEVA, Boehringer Ingelheim, Novartis, GlaxoSmithKline, and MEDA; has received payment for lectures from AstraZeneca, MEDA, Novartis, UCB, Boehringer Ingelheim, MSD, Pfizer, Grunenthal, Siegfried, and Armstrong; has received payment for development of educational presentations from Grunenthal; and is on the safety board for DBV. K. C. LodrupCarlsen has received travel support from the European Respiratory Society. E. Meltzer has consultant arrangements with Allergan, AstraZeneca, Boehringer Ingelheim, GlaxoSmithKline, Greer, Merck, Mylan, Regeneron-Sanofi, and Teva and has received payment for lectures from GlaxoSmithKline, Greer, Merck, Mylan, and Teva. J. Mullol has board memberships with Uriach, FAES, ALK-Abelló, Sanofi, Genentech, and MEDA; has received grants from Meda, FAES, Uriach, GlaxoSmithKline, MSD; and has received payment for lectures from Uriach, Sanofi, MSD, Novartis, Menarini, MEDA, and UCB. A. Muraro has consultant arrangements with MEDA, Novartis, and Menarini; is employed by Padua University Hospital; and has received payment for lectures from MEDA and Menarini. K. Ohta has received payment for lectures from Kyorin, AstraZeneca, Astellas, and Boehringer Ingelheim. P. Panzner has board memberships with Allergy Therapeutics, Teva, and Novartis; has consultant arrangements with ALK-Abelló, ASIT Biotech, and AstraZeneca; and has received payment for lectures from Shire and Stallergenes. N. Papadopoulos is on advisory boards for Novartis, Faes Farma, BIOMAY, HAL, and Nutricia Research; has consultant arrangements with Menarini, ALK-Abelló, Novartis, MEDA, and Chiesi; has received grants from NESTEC and Menarini; and has received payment for lectures from Stallergenes, AbbVie, Novartis, MEDA, MSD, Omega Pharma, and Danone. R. Pawankar is employed by Nippon Medical School and has received a grant from the Japanese Ministry of Education. D. Price has board memberships with Aerocrine, Amgen, AstraZeneca, Boehringer Ingelheim, Chiesi, Meda, Mundipharma, Napp, Novartis, and Teva; has consultant arrangements with Almirall, Amgen, AstraZeneca, Boehringer Ingelheim, Chiesi, GlaxoSmithKline, Meda, Mundipharma, Napp, Novartis, Pfizer, Teva, and Theravance; has received grants from Aerocrine, AKL Research and Development, AstraZeneca, Boehringer Ingelheim, British Lung Foundation, Chiesi, Meda, Mundipharma, Napp, Novartis, Pfizer, Respiratory Effectiveness Group, Takeda, Teva Pharmaceuticals, Theravance, UK National Health Service, and Zentiva; has received payment for lectures from Almirall, AstraZeneca, Boehringer Ingelheim, Chiesi, Cipla, GlaxoSmithKline, Kyorin, Meda, Merck, Mundipharma, Novartis, Pfizer, Skyepharma, Takeda, and Teva Pharmaceuticals; has received payment for manuscript preparation from Mundipharma and Teva; has received payment for development of education presentations from Mundipharma and Novartis; owns shares in AKL Research and Development; has received travel support from Aerocrine, AstraZeneca, Boehringer Ingelheim, Mundipharma, Napp, Novartis, and Teva Pharmaceuticals; has received funding for patient enrollment or completion of research from Chiesi, Novartis, Teva Pharmaceuticals, and Zentiva; has served as a peer reviewer for grant committees for Efficacy and Mechanism Evaluation programme, Health Technology Assessment, and Medical Research Council; and owns $74 \%$ of Optimum Patient Care and $74 \%$ of Observational and Pragmatic Research Institute Pte. D. Ryan is on advisory panels for Uriah and Stallergenes; has received payment for lectures and payment for development of education presentations from MEDA; has board memberships with Stallergenes; has had consultant arrangements with Uriach; and is director of Respiratory Effectiveness Group. B. Samolinski has received travel support from Meda; has received grants from the National Science Center and the Ministry of Health; has received payment for lectures from Polfarma, Adamed, Teva, and Meda; has received payment for manuscript preparation from Adamed, Teva, Meda; has received payment for development of educational presentations from Teva and Adamed; and has received travel support from Meda and Adamed. P. Schmid-Grendelmeier has consultant arrangements with Novartis Pharma and Meda Pharma, has received grants from Novartis, and has received payment for lectures from Novartis. A. Sheikh has received payment to develop guidelines on allergen immunotherapy from the European Academy of Allergy and Clinical Immunology. D. Wallace has consultant arrangements with MEDA and has received payment for lectures from MEDA and Mylan. S. Waserman has consultant arrangements with Merck, GlaxoSmithKline, Novartis, CSL Behring, Shire, Sanofi Canada, Aralez, Pediapharm, Mylan, and Meda; is employed by McMaster University; has received grants from Pfizer Canada; has received payment for lectures from Merck, CSL Behring, Shire, AstraZeneca, Pfizer, Sanofi, Pediapharm, and Aralez; has received payment for development of educational presentations from Merck; and has received travel support from Pediapharm. M. Wickman has consultant arrangements from Meda. T. Zuberbier has received institutional funding for research and/or honoraria for lectures and/or consulting from AstraZeneca, AbbVie, ALK-Abelló, Almirall, Astellas, Bayer Health Care, Bencard, Berlin Chemie, FAES, HAL, Henkel, Kryolan, Leti, L'Oreal, Meda, Menarini, Merck, MSD, Novartis, Pfizer, Sanofi, Stallergenes, Takeda, Teva and UCB and is a member of ARIA/World Health Organization, DGAKI, ECARF, $\mathrm{GA}^{2} \mathrm{LEN}$ and WAO. H. J. Schünemann has received partial support for developing systematic reviews for these guidelines from the ARIA Initiative. The rest of the authors declare that they have no relevant conflicts of interest.

Received for publication October 3, 2016; revised February 12, 2017; accepted for publication March 15, 2017.

Corresponding author: Jan L. Brożek, MD, PhD, McMaster University, Department of Clinical Epidemiology and Biostatistics, Hamilton, Ontario L8S 4K1, Canada. E-mail: jan.1.brozek@gmail.com.

0091-6749/\$36.00

(C) 2017 American Academy of Allergy, Asthma \& Immunology http://dx.doi.org/10.1016/j.jaci.2017.03.050 
Methods: The ARIA guideline panel identified new clinical questions and selected questions requiring an update. We performed systematic reviews of health effects and the evidence about patients' values and preferences and resource requirements (up to June 2016). We followed the Grading of Recommendations Assessment, Development, and Evaluation (GRADE) evidence-to-decision frameworks to develop recommendations.

Results: The 2016 revision of the ARIA guidelines provides both updated and new recommendations about the pharmacologic treatment of AR. Specifically, it addresses the relative merits of using oral $\mathrm{H}_{1}$-antihistamines, intranasal $\mathrm{H}_{1}$-antihistamines, intranasal corticosteroids, and leukotriene receptor antagonists either alone or in combination. The ARIA guideline panel provides specific recommendations for the choice of treatment and the rationale for the choice and discusses specific considerations that clinicians and patients might want to review to choose the management most appropriate for an individual patient.

Conclusions: Appropriate treatment of AR might improve patients' quality of life and school and work productivity. ARIA recommendations support patients, their caregivers, and health care providers in choosing the optimal treatment. ( $J$ Allergy Clin Immunol 2017;

Key words: Allergic rhinitis, practice guideline

Allergic rhinitis (AR) is among the most common diseases globally and usually persists throughout life. ${ }^{1}$ The prevalence of self-reported AR has been estimated to be approximately $2 \%$ to $25 \%$ in children ${ }^{2}$ and $1 \%$ to greater than $40 \%$ in adults. ${ }^{1,3}$ The prevalence of confirmed AR in adults in Europe ranged from $17 \%$ to $28.5 \%$. Recent studies show that the prevalence of AR has increased in particular in countries with initial low prevalence (for a discussion of prevalence of AR, see section 5.1-5.2 in Allergic Rhinitis and its Impact on Asthma [ARIA] 2008 Update $^{1}$ ). Classical symptoms of AR are nasal itching, sneezing, rhinorrhea, and nasal congestion. Ocular symptoms are also frequent; allergic rhinoconjunctivitis is associated with itching and redness of the eyes and tearing. Other symptoms include itching of the palate, postnasal drip, and cough.

$\mathrm{AR}$ is also frequently associated with asthma, which is found in $15 \%$ to $38 \%$ of patients with $\mathrm{AR},{ }^{4,5}$ and nasal symptoms are present in $6 \%$ to $85 \%$ patients with asthma. ${ }^{6-9}$ In addition, AR is a risk factor for asthma, ${ }^{4,9}$ and uncontrolled moderate-to-severe AR affects asthma control. ${ }^{10,11}$

Compared with other medical conditions, AR might not appear to be serious because it is not associated with severe morbidity and mortality. However, the burden and costs are substantial. ${ }^{12}$ AR reduces the quality of life of many patients, impairing sleep quality and cognitive function and causing irritability and fatigue. $\mathrm{AR}$ is associated with decreased school and work performance, especially during the peak pollen season. ${ }^{1} \mathrm{AR}$ is a frequent reason for general practice office visits. Annual direct medical costs of AR are substantial, but indirect costs associated with lost work productivity are greater than those incurred by asthma. ${ }^{13-15}$ Appropriate treatment of AR improves symptoms, quality of life, and work and school performance.

Clinical practice guidelines for AR management were developed over the past 20 years $^{16}$ and have improved the care of

\author{
Abbreviations used \\ AR: Allergic rhinitis \\ ARIA: Allergic Rhinitis and its Impact on Asthma \\ EtD: Evidence to decision \\ GRADE: Grades of Recommendation, Assessment, Development, \\ and Evaluation \\ ICP: Integrated care pathway \\ PAR: Perennial allergic rhinitis \\ SAR: Seasonal allergic rhinitis \\ SMD: Standardized mean difference
}

patients with AR. ${ }^{17}$ However, transparent reporting of guidelines to facilitate understanding and acceptance are needed. The ARIA initiative was initiated during a World Health Organization workshop in $1999^{18}$ and updated in 2008. ${ }^{1}$ The ARIA 2010 revision was the first evidence-based guideline in allergy to follow the Grading of Recommendations, Assessment, Development, and Evaluation (GRADE) approach ${ }^{19}$ with no influence of for-profit organizations and an explicit declaration and management of potential competing interests of panel members. ${ }^{20}$ It summarized the potential benefits and harms underlying the recommendations, as well as assumptions around values and preferences that influenced the strength and direction of the recommendations. In 2014, the ARIA revision was found to rank first in the rigor of development and quality of reporting of guidelines about the management of $\mathrm{AR},{ }^{16}$ although recent guidelines published later were not considered. ${ }^{2}$

\section{CLINICAL QUESTIONS}

Since the last revision of the ARIA guidelines in $2010,{ }^{20}$ new treatments have become available, and new evidence has accumulated about selected other treatments. By using a modified Delphi process, the ARIA guideline panel selected new questions that required answering with recommendations or the existing recommendations that required an updated review of the evidence and potentially updating the recommendations themselves. Therefore this revision of the ARIA guidelines is limited in scope and addresses 6 questions about the treatment of AR:

1. Should a combination of oral $\mathrm{H}_{1}$-antihistamine and intranasal corticosteroid versus intranasal corticosteroid alone be used for treatment of AR?

2. Should a combination of intranasal $\mathrm{H}_{1}$-antihistamine and intranasal corticosteroid versus intranasal corticosteroid alone be used for treatment of AR?

3. Should a combination of an intranasal $\mathrm{H}_{1}$-antihistamine and an intranasal corticosteroid versus intranasal $\mathrm{H}_{1}$-antihistamine alone be used for treatment of AR?

4. Should a leukotriene receptor antagonist versus an oral $\mathrm{H}_{1^{-}}$ antihistamine be used for treatment of AR?

5. Should an intranasal $\mathrm{H}_{1}$-antihistamine versus an intranasal corticosteroid be used for treatment of AR?

6. Should an intranasal $\mathrm{H}_{1}$-antihistamine versus an oral $\mathrm{H}_{1}$ antihistamine be used for treatment of AR?

The target audience of these guidelines is primary care clinicians, school nurses, pharmacists, specialists in allergy and clinical immunology, general internists managing patients with $\mathrm{AR}$, and pediatricians. Ear-nose-throat specialists, other health 
care professionals, and health care policy makers can also benefit from these guidelines.

\section{CLASSIFICATION OF AR}

The classification of AR was revised by ARIA in 2001. A major change was the introduction of the terms "intermittent" and "persistent." ${ }^{18}$ Before then, AR was classified, based on the time and type of exposure and symptoms, into seasonal allergic rhinitis (SAR; most often caused by outdoor allergens, such as pollens or molds), perennial allergic rhinitis (PAR; most frequently, although not necessarily, caused by indoor allergens such as house dust mites, molds, cockroaches, and animal dander), and occupational allergic rhinitis. ${ }^{22,23}$ With very few exceptions, published studies refer to SAR and PAR and enroll patients based on the offending allergen (pollen, house dust mites, or both), and we retained the terms SAR and PAR to enable the interpretation of published evidence.

The recommendations in the ARIA 2016 update apply directly to patients with moderate-to-severe AR. They might be less applicable to treatment of patients with mild AR who frequently do not seek medical help and manage their symptoms themselves with medications available other the counter.

\section{RECOMMENDATIONS FOR CHILDREN}

Almost all studies used to answer the questions in this update of the ARIA guidelines included exclusively adult patients. However, careful extrapolation to the pediatric population can be attempted. One can assume that the relative effects of treatment of AR are likely similar among adults and children, but adverse effects might be more or less frequent, and their perception and importance might be different (eg, bitter taste). Values and preferences for specific outcomes and treatments can also vary between adults and children.

\section{METHODOLOGY}

The full description of methods used to develop recommendations in these guidelines is described in the Methods section of the full version of the guideline document (see Online Repository item E1 in this article's Online Repository at www.jacionline. org). Here we describe briefly the methodology to facilitate the interpretation of the guidelines.

\section{Questions and outcomes of interest}

The scope and questions for this update of the ARIA guidelines were identified by the ARIA guideline panel members. The guideline panel deemed the following outcomes to be important to patients: nasal and ocular symptoms, quality of life, work/ school performance, and adverse effects. As for the previous revision of the ARIA guidelines, we did not formally assess the relative importance of each outcome of interest (ie, which outcomes are more and which are less important) but rather adopted the rating agreed upon by the guideline panel according to the structured discussion. ${ }^{24}$ In general, combined nasal symptoms, ocular symptoms, quality of life, work/school performance, and serious adverse effects were considered critical to the decision, and individual symptoms, a composite outcome of any adverse effects and adverse effects that were not serious or did not lead to discontinuation of treatment, were considered important but not critical (see evidence profiles in Online Repository item E2 in this article's Online Repository at www.jacionline. org).

\section{Evidence review and development of clinical recommendations}

For each question, the methodology group performed a full systematic review of the literature to identify and summarize evidence about the effects of interventions on the outcomes of interest. We also searched systematically for information about patients' values and preferences and resource use (cost). We systematically searched the Medline, Embase, and Cochrane CENTRAL electronic databases. Titles and abstracts and subsequently full-text articles were screened in duplicate to assess eligibility according to prespecified criteria. Panel members were contacted to confirm completeness of the body of evidence and suggest additional articles that might have been missed in electronic searches.

To obtain the estimates of effects on each outcome of interest, we performed meta-analyses using the Cochrane Collaboration Review Manager Software, version 5.3.5. ${ }^{25}$ We prepared evidence summaries (see Online Repository item E2) for each question according to the GRADE approach $^{19}$ by using the GRADEpro Guideline Development Tool online application (www.gradepro.org).

When continuous outcomes (eg, symptom scores or quality of life) are measured by using different scales, the results can only be combined in meta-analysis by using the standardized mean difference (SMD), which is expressed in SD units. ${ }^{26}$ Results expressed as an SMD are challenging to interpret. To facilitate understanding, we used interpretation of the effect size according to Cohen conventional criteria ${ }^{27}$ : an SMD of around 0.2 is considered a small effect, an SMD of around 0.5 is considered a moderate effect, and an SMD of around 0.8 or higher is considered a large effect. We used this interpretation throughout this document when we referred to effects of interventions as small, moderate, or large.

We assessed the risk of bias at the outcome level by using the Cochrane Collaboration's risk of bias tool. ${ }^{28}$ Subsequently, we assessed the certainty of the body of evidence (ie, confidence in the estimated effects, which is also known as "quality of the evidence") for each of the outcomes of interest according to the GRADE approach ${ }^{29}$ based on the following criteria: risk of bias, precision, consistency and magnitude of the estimates of effects, directness of the evidence, risk of publication bias, presence of a dose-effect relationship, and assessment of the effect of residual opposing confounding. Certainty of the evidence was categorized into 4 levels: high, moderate, low, and very low.

For each question, we summarized all information in evidenceto-decision (EtD) frameworks (see Online Repository item E2) that included concise description of desirable and undesirable health effects, certainty of the evidence about those effects, evidence and assumptions about patients' values and preferences, required resources and cost-effectiveness, potential influence on health equity, acceptability of the intervention to various stakeholders, and feasibility of implementation. ${ }^{30}$ Judgments about all these factors and suggested recommendations in EtD frameworks were drafted by J.L.B., who was also a clinical expert. 
EtDs for all questions were reviewed by the ARIA guideline panel members, who provided feedback by means of electronic communication and during a face-to-face meeting of Integrated Care Pathways for Airway Diseases (AIRWAYS ICPs) ${ }^{31,32}$ and Frailty European Innovation Partnership on Active and Healthy Ageing Reference Sites in Lisbon, Portugal on July 1, 2015. All comments were addressed, and the frameworks were modified accordingly. Modified EtD frameworks that included judgments about the research evidence, additional considerations of ARIA panel members, and draft recommendations were sent to all ARIA panel members for review and approval or disapproval and comments by using the online SurveyMonkey software (www.surveymonkey.com). We recorded and addressed all agreements/disagreements, comments, and suggestions for changes. We present the final EtD frameworks in Online Repository item E2.

Recommendations and their strength were decided by consensus. The ARIA guideline panel agreed on the final wording of recommendations and remarks with further qualifications for each recommendation. The final document, including the recommendations, was reviewed and approved by all members of the guideline panel.

According to the GRADE approach, the recommendations can be either "strong" or "conditional" depending on the guideline panel's confidence that following the recommendation would bring more good than harm to patients. The wording of recommendations reflects their strength, and one can use the terms "we recommend" for strong recommendations and "we suggest" for conditional recommendations. Box 1 provides suggested interpretation of strong and conditional recommendations.

\section{Recommendations}

We present all recommendations in Table I. We provide the rationale for the recommendations and the consideration of all factors that influenced the recommendations: effects on all important health outcomes, certainty of the available evidence, values and preferences, acceptability by stakeholders, requirements for resources, feasibility, and any issues of health equity in the unabridged guideline document in Online Repository item E1. Detailed summaries of the evidence supporting each recommendation and the guideline panel judgements are shown in Online Repository item E2.

\section{How to use these guidelines}

The ARIA guidelines about treatment of AR are not intended to impose a standard of care for individual countries. They provide the basis for rational informed decisions for patients, parents, clinicians, and other health care professionals. Clinicians, patients, third-party payers, institutional review committees, other stakeholders, or the courts should not view these recommendations as dictates. Recommendations provide guidance for typical patients; no recommendation can take into account all of the often-compelling unique individual circumstances. Thus, no one charged with evaluating health care professionals' actions should apply the recommendations from these guidelines by rote or in a blanket fashion.

Statements regarding the underlying values and preferences, as well as qualifying remarks accompanying each recommendation,
Box 1. Strength of recommendation

\section{Strong recommendation}

For patients: Most patients in this situation would want the recommended course of action, and only a small proportion would not.

For clinicians: Most patients should receive the intervention. Adherence to a strong recommendation could be used as a quality criterion or performance indicator. Formal decision aids are not likely to be needed to help patients make decisions consistent with their values and preferences.

For health care policy makers: The recommendation can be adopted as a policy or performance measure in most situations.

\section{Conditional recommendation}

For patients: The majority of patients in this situation would want the suggested course of action, but many would not. For clinicians: Recognize that different choices will be appropriate for individual patients and that you must help each patient arrive at a management decision consistent with his or her values and preferences. Decision aids might be useful in helping patients to make decisions consistent with their values and preferences.

For health care policy makers: Policy making will require substantial debate and involvement of various stakeholders. Documentation of appropriate (eg, shared) decision-making processes can serve as a performance measure.

should never be omitted when quoting or translating recommendations from these guidelines.

\section{CONCLUSIONS}

Evidence-based guidelines are at the cornerstone of integrated care pathways (ICPs), ${ }^{31,32}$ structured multidisciplinary care plans that promote translation of guideline recommendations into local protocols and their subsequent application in clinical practice. Usually, several guidelines are available providing advice about the management of the same condition. ${ }^{16}$ It is important to wisely choose appropriate guidelines for local adaptation and creation of ICPs because most of them have limitations because of either the development of the guideline itself or the available research evidence and its interpretation. The most common limitations of guidelines in AR are narrowness in scope (addressing only a small selection of important questions about the management of a given condition), suboptimal rigor of development and reporting, and inadequate representation of the views of patients and their caregivers. ${ }^{16}$ We acknowledge that for the ARIA 2016 update, we have not reviewed all recommendations from the ARIA 2010 guidelines. However, we updated only 3 recommendations suggested by the ARIA panel members as requiring the update, and we addressed 3 new questions. We also acknowledge that the ARIA guideline panel included allergists, ear-nose-throat specialists, pulmonologists, general practitioners, and pediatricians but did not include other health care professionals, pharmacists, and patients themselves. However, for the ARIA 2016 update, we systematically searched and reviewed the published evidence about the patients' values and preferences regarding the outcomes and treatments for AR that to certain degree helped to overcome this limitation. We summarized the results in the section about the assumed 
TABLE I. Recommendations

Question 1: Should a combination of an oral H1-antihistamine (OAH) and intranasal corticosteroid (INCS) vs INCS alone be used for treatment of AR?

Recommendation 1A: In patients with SAR, we suggest either a combination of an INCS with an $\mathrm{OAH}$ or an INCS alone (conditional recommendation | low certainty of evidence).
ARIA guideline panel acknowledged that the choice of treatment would depend mostly on patient preferences and local availability and cost of treatment. Panel members assumed that in the majority of situations, potential net benefit would not justify spending additional resources.
Recommendation 1B: In patients with PAR, we suggest an INCS alone rather than a combination of an INCS with an OAH (conditional recommendation | very low certainty of evidence).

This is a conditional recommendation, and thus different choices will be appropriate for different patients. In settings in which the additional cost of an $\mathrm{OAH}$ is not large and/or patients' values and preferences differ from those assumed by guideline panel members, a combination therapy might be a reasonable choice, especially in patients whose symptoms are not well controlled with an INCS alone, those with pronounced ocular symptoms, or those commencing treatment because of likely faster onset of treatment effects.

This recommendation concerns regular use of newer and less sedative OAHs and INCSs in patients with SAR. For older OAHs with more sedative effects, the balance of desirable and undesirable effects may be different.

Currently available evidence suggests that there is no additional benefit from a combination therapy compared with INCS alone, and there might be additional undesirable effects. This recommendation is conditional because of sparse information and thus very low certainty of the estimated effects

Question 2: Should a combination of an intranasal $\mathrm{H}_{1}$-antihistamine (INAH) and INCS vs an INCS alone be used for treatment of AR?

Recommendation 2A: In patients with SAR, we The panel members acknowledged that the choice suggest either a combination of an INCS with of treatment will mostly depend on patient an INAH or an INCS alone (conditional recommendation | moderate certainty of evidence).

Recommendation 2B: In patients with PAR, we suggest either a combination of an INCS with an INAH or an INCS alone (conditional recommendation | very low certainty of evidence).

Question 3: Should a combination of an INAH and INCS vs an INAH alone be used for treatment of AR?

Recommendation 3A: In patients with SAR, we This recommendation places higher value on suggest a combination of an INCS with an INAH rather than an INAH alone (conditional recommendation | low certainty of evidence) preferences and local availability and cost of treatment. At initiation of treatment (approximately the first 2 weeks), a combination of an INCS with an INAH might act faster than an INCS alone and thus might be preferred by some patients.

The panel members acknowledged that the choice of treatment will mostly depend on patient preferences and local availability and cost of treatment. additional reduction of symptoms and improved quality of life with a combination therapy compared with an INAH alone. It places a lower value on avoiding additional cost (expenditure of resources).
This is a conditional recommendation, and thus different choices will be appropriate for different patients. In settings in which the additional cost of combination therapy is not large and/or patients value potential benefits more than any increased risk of adverse effects, a combination therapy might be a reasonable choice.

This is a conditional recommendation because of the very low certainty of the evidence. At the initiation of treatment (approximately the first 2 weeks), combination of an INCS with an INAH might act faster than an INCS alone and thus might be preferred by some patients.

Question 4: Should a leukotriene receptor antagonist (LTRA) vs an OAH be used for treatment of AR?

Recommendation 4A: In patients with SAR, we suggest either an LTRA or an OAH (conditional recommendation | moderate certainty of evidence).
Panel members acknowledged that the choice of an LTRA or OAH will mostly depend on patient preferences and local availability and cost of specific medications. In many settings an $\mathrm{OAH}$ might still be more cost-effective, but this will largely depend on availability of generic LTRAs and the local cost of various newer-generation OAHs and LTRAs.
This is a conditional recommendation, and thus different choices will be appropriate for different patients. In settings in which the additional cost of a combination therapy is large, an alternative choice (ie, and INAH alone) might be equally reasonable. One panel member thought that the recommendation should be conditional for either the intervention or comparison.

Some patients with AR who have concomitant asthma, especially exercise-induced and/or aspirin-exacerbated respiratory disease, might benefit from an LTRA more than from an $\mathrm{OAH}$ However, this recommendation applies to treatment of AR but not to treatment of asthma. Patients with asthma who have concomitant AR should receive an appropriate treatment according to the guidelines for the treatment of asthma. 
Recommendation 4B: In patients with PAR, we suggest an OAH rather than a LTRA (conditional recommendation | low certainty of evidence).
This recommendation places a higher value on possibly larger improvement of symptoms and quality of life with an OAH compared with an LTRA. It places a lower value on possible increased risk of somnolence.
Question 5: Should an INAH vs an INCS be used for treatment of AR?

Recommendation 5A: In patients with SAR, we suggest an INCS rather than an INAH (conditional recommendation | moderate certainty of evidence)

Recommendation 5B: In patients with PAR, we suggest an INCS rather than an INAH (conditional recommendation | low certainty of evidence).

Question 6: Should an INAH vs an OAH be used fo

Recommendation 6A: In patients with SAR, we suggest either an INAH or OAH (conditional recommendation | low certainty of evidence)

Recommendation 6B: In patients with PAR, we suggest either an INAH or OAH (conditional recommendation | very low certainty of evidence).
This recommendation places a higher value on likely small but greater reduction of symptoms and improvement of quality of life with an INCS compared with an INAH and a lower value on avoiding larger cost of treatment with an INCS in many jurisdictions.

This recommendation places a higher value on probably greater reduction of nasal symptoms with an INCS compared with an INAH, although the overall difference is likely small. It places a lower value on avoiding larger cost of treatment with an INCS in many jurisdictions.

The panel members acknowledged that the choice of treatment will depend mostly on patient preferences and local availability and cost of treatment.

The panel members acknowledged that the choice of treatment will mostly depend on patient preferences and local availability and cost of treatment.
This is a conditional recommendation, and thus different choices will be appropriate for different patients based on their preferences for reduction of symptoms vs avoiding the risk of adverse effects. This might be more important for patients with PAR than those with SAR because they might use those medications for longer periods of time. Some patients with AR and concomitant asthma, especially exercise-induced and/or aspirinexacerbated respiratory disease, might benefit from an LTRA more than from an OAH. However, this recommendation applies to treatment of AR but not to treatment of asthma. Patients with asthma who have concomitant $\mathrm{AR}$ should receive an appropriate treatment according to the guidelines for the treatment of asthma.

This is a conditional recommendation, and thus different choices will be appropriate for different patients. Clinicians must help each patient to arrive at a decision consistent with her or his values and preferences, considering loca availability and costs.

This is a conditional recommendation, and thus different choices will be appropriate for different patients. Clinicians must help each patient to arrive at a decision consistent with her or his values and preferences, considering local availability and costs.

This is a conditional recommendation, and thus different choices will be appropriate for different patients. Clinicians must help each patient to arrive at a decision consistent with her or his preferences, considering local availability, coverage, and costs.

This is a conditional recommendation, and thus different choices will be appropriate for different patients. Clinicians must help each patient to arrive at a decision consistent with her or his preferences, considering local availability, coverage, and costs.

$I N A H$, Intranasal $\mathrm{H}_{1}$-antihistamine; INCS, intranasal corticosteroid; LTRA, leukotriene receptor antagonist; $O A H$, oral $\mathrm{H}_{1}$-antihistamine

values and preferences in the full text of the ARIA 2016 update (see Online Repository item E1) and in the relevant sections of EtD tables (see Online Repository item E2).

The available evidence has important limitations: (1) selective measurement and reporting of outcomes (eg, few studies properly measure and report quality of life, which is the most important outcome in patients with AR), (2) selection of patients for clinical trials that might not represent appropriately the patients seen in primary care, ${ }^{34}$ and (3) not distinguishing between patients with different age or severity of symptoms (lack of proper stratification), ${ }^{35}$ thus limiting the applicability and generalizability of the research findings. Given these limitations, clinical practice guidelines, especially those with international audience, should emphasize rigorous systematic review of the health effects and explicit and detailed description of the assumed values and preferences and considerations of cost, feasibility, acceptability, and health equity issues because it is currently following the GRADE EtD frameworks. ${ }^{36-38}$ Such detailed, explicit, and transparent reporting of guidelines facilitates local adaptation of recommendations and their translation into ICPs. Systematic and transparent summaries of the evidence clearly identifying gaps in available research evidence are needed to direct the research agenda and to avoid unnecessary expenditure of resources for further clinical research when it is not necessary. ${ }^{39}$

Implementation of guidelines in different settings and countries depends on the availability of health interventions (eg, medical tests, medications, and equipment), availability of resources, and cultural differences, among others. Thus local adaptation of recommendations can be required, and ICPs need to be developed at the national, regional, or local level. However, 
they should always be based on systematically reviewed evidence of desirable and undesirable consequences. The ARIA 2016 revision will be used to develop the ICPs proposed by the European Innovation Partnership on Active and Healthy Ageing ${ }^{31,32,40}$ by using MASK (MACVIA-ARIA Sentinel Network). ARIA is developing a novel implementation strategy using mobile technology ${ }^{41,42}$ and a clinical decision support system $^{41}$ that is deployed in 21 countries. $^{43}$ The ARIA 2016 revision will be embedded in the clinical decision support system for real-time patient stratification by using mobile technology.

Most of the recommendations are based on low- or very lowcertainty evidence, mainly because of the imprecision of the estimated effects due to few patients being studied. For those questions, there is a need for more well-designed and executed randomized controlled trials that would measure and properly report all important outcomes.

Clinical implications: The 2016 revision of the ARIA guidelines offers updated advice for clinicians and patients about the most commonly used treatments for AR.

\section{REFERENCES}

1. Bousquet J, Khaltaev N, Cruz AA, Denburg J, Fokkens WJ, Togias A, et al Allergic Rhinitis and its Impact on Asthma (ARIA) 2008 update (in collaboration with the World Health Organization, GA(2)LEN and AllerGen). Allergy 2008; 63(suppl 86):8-160.

2. Asher MI, Montefort S, Bjorksten B, Lai CK, Strachan DP, Weiland SK, et al Worldwide time trends in the prevalence of symptoms of asthma, allergic rhinoconjunctivitis, and eczema in childhood: ISAAC Phases One and Three repeat multicountry cross-sectional surveys. Lancet 2006;368:733-43.

3. Katelaris CH, Lee BW, Potter PC, Maspero JF, Cingi C, Lopatin A, et al. Prevalence and diversity of allergic rhinitis in regions of the world beyond Europe and North America. Clin Exp Allergy 2012;42:186-207.

4. Leynaert B, Bousquet J, Neukirch C, Liard R, Neukirch F. Perennial rhinitis: an independent risk factor for asthma in nonatopic subjects: results from the European Community Respiratory Health Survey. J Allergy Clin Immunol 1999;104:301-4.

5. Gergen PJ, Turkeltaub PC. The association of individual allergen reactivity with respiratory disease in a national sample: data from the second National Health and Nutrition Examination Survey, 1976-80 (NHANES II). J Allergy Clin Immunol 1992;90:579-88.

6. Sibbald B, Rink E. Epidemiology of seasonal and perennial rhinitis: clinical presentation and medical history. Thorax 1991;46:895-901.

7. Pedersen PA, Weeke ER. Asthma and allergic rhinitis in the same patients. Allergy 1983;38:25-9.

8. Greisner W, Settipane RJ, Settipane GA. Co-existence of asthma and allergic rhinitis: a 23-year follow-up study of college students. Allergy Asthma Proc 1998;19:185-8

9. Guerra S, Sherrill DL, Baldacci S, Carrozzi L, Pistelli F, Di Pede F, et al. Rhinitis is an independent risk factor for developing cough apart from colds among adults Allergy 2005;60:343-9.

10. Corren J, Adinoff AD, Buchmeier AD, Irvin CG. Nasal beclomethasone prevents the seasonal increase in bronchial responsiveness in patients with allergic rhinitis and asthma. J Allergy Clin Immunol 1992;90:250-6.

11. Taramarcaz P, Gibson PG. Intranasal corticosteroids for asthma control in people with coexisting asthma and rhinitis. Cochrane Database Syst Rev 2003;(3):CD003570.

12. Zuberbier T, Lotvall J, Simoens S, Subramanian SV, Church MK. Economic burden of inadequate management of allergic diseases in the European Union: a GA(2) LEN review. Allergy 2014;69:1275-9.

13. Haahtela T, Valovirta E, Hannuksela M, von Hertzen L, Jantunen J, Kauppi P, et al. Finnish nationwide allergy programme at mid-term — change of direction producing results. Finnish Med J 2015;70:2165-72.

14. Thanaviratananich S, Cho SH, Ghoshal AG, Muttalif AR, Lin HC, Pothirat C, et al. Burden of respiratory disease in Thailand: results from the APBORD observational study. Medicine (Baltimore) 2016;95:e4090.

15. Yoo KH, Ahn HR, Park JK, Kim JW, Nam GH, Hong SK, et al. Burden of respi ratory disease in Korea: an observational study on allergic rhinitis, asthma, COPD, and rhinosinusitis. Allergy Asthma Immunol Res 2016;8:527-34.
16. Padjas A, Kehar R, Aleem S, Mejza F, Bousquet J, Schunemann HJ, et al. Methodological rigor and reporting of clinical practice guidelines in patients with allergic rhinitis: QuGAR study. J Allergy Clin Immunol 2014;133:777-83.e4.

17. Bousquet J, Lund VJ, Van Cauwenberge P, Bremard-Oury C, Mounedji N, Stevens MT, et al. Implementation of guidelines for seasonal allergic rhinitis: a randomized controlled trial. Allergy 2003;58:733-41.

18. Bousquet J, Van Cauwenberge P, Khaltaev N. Allergic rhinitis and its impact on asthma. J Allergy Clin Immunol 2001;108(suppl):S147-334.

19. Guyatt G, Oxman AD, Akl EA, Kunz R, Vist G, Brozek J, et al. GRADE guidelines: 1. Introduction-GRADE evidence profiles and summary of findings tables. J Clin Epidemiol 2011;64:383-94.

20. Brożek JL, Bousquet J, Baena-Cagnani CE, Bonini S, Canonica GW, Casale TB, et al. Allergic Rhinitis and its Impact on Asthma (ARIA) guidelines: 2010 revision. J Allergy Clin Immunol 2010;126:466-76.

21. Seidman MD, Gurgel RK, Lin SY, Schwartz SR, Baroody FM, Bonner JR, et al. Clinical practice guideline: allergic rhinitis. Otolaryngol Head Neck Surg 2015; 152(suppl):S1-43.

22. Dykewicz MS. 7. Rhinitis and sinusitis. J Allergy Clin Immunol 2003;111(suppl): S520-9.

23. van Cauwenberge P, Bachert C, Passalacqua G, Bousquet J, Canonica GW, Durham SR, et al. Consensus statement on the treatment of allergic rhinitis. European Academy of Allergology and Clinical Immunology. Allergy 2000;55:116-34.

24. Guyatt GH, Oxman AD, Kunz R, Atkins D, Brozek J, Vist G, et al. GRADE guidelines: 2. Framing the question and deciding on important outcomes. J Clin Epidemiol 2011;64:395-400

25. The Nordic Cochrane Centre. Review manager (RevMan) [Computer program]. Version 5.3.5. Copenhagen: The Cochrane Collaboration; 2014.

26. Deeks JJ, Higgins JPT, Altman DG, on behalf of the Cochrane Statistical Methods Group. The standardized mean difference. In: Higgins JPT, Green S, editors. Cochrane handbook for systematic reviews of interventions version 5.0.1 [updated September 2008]. Available at: http://www.cochrane-handbook.org/.

27. Cohen J. Statistical power analysis for the behavioral sciences. 2nd ed. New York: Routledge; 1988.

28. Higgins JP, Altman DG, Gotzsche PC, Juni P, Moher D, Oxman AD, et al. The Cochrane Collaboration's tool for assessing risk of bias in randomised trials. BMJ 2011;343:d5928.

29. Balshem H, Helfand M, Schunemann HJ, Oxman AD, Kunz R, Brozek J, et al. GRADE guidelines: 3. Rating the quality of evidence. J Clin Epidemiol 2011; 64:401-6.

30. Schunemann HJ, Mustafa R, Brozek J, Santesso N, Alonso-Coello P, Guyatt G, et al. Development of the GRADE Evidence to Decision (EtD) frameworks for tests in clinical practice and public health. J Clin Epidemiol 2016;76: 89-98.

31. Bousquet J, Barbara C, Bateman E, Bel E, Bewick M, Chavannes NH, et al. AIRWAYS-ICPs (European Innovation Partnership on Active and Healthy Ageing) from concept to implementation. Eur Respir J 2016;47:1028-33.

32. Bousquet J, Addis A, Adcock I, Agache I, Agusti A, Alonso A, et al. Integrated care pathways for airway diseases (AIRWAYS-ICPs). Eur Respir J 2014;44: 304-23.

33. Bousquet J, Pinto JR, Barbara C, da Sousa JC, Fonseca J, Miguel JP, et al. Portugal at the cross road of international chronic respiratory programmes. Rev Port Pneumol (2006) 2015;21:230-2.

34. Costa DJ, Amouyal M, Lambert P, Ryan D, Schunemann HJ, Daures JP, et al. How representative are clinical study patients with allergic rhinitis in primary care? J Allergy Clin Immunol 2011;127:920-6.e1.

35. Bousquet J, Bachert C, Canonica GW, Casale TB, Cruz AA, Lockey RJ, et al. Unmet needs in severe chronic upper airway disease (SCUAD). J Allergy Clin Immunol 2009; 124:428-33.

36. Alonso-Coello P, Oxman AD, Moberg J, Brignardello-Petersen R, Akl EA, Davoli M, et al. GRADE Evidence to Decision (EtD) frameworks: a systematic and transparent approach to making well informed healthcare choices. 2: Clinical practice guidelines. BMJ 2016;353:i2089.

37. Alonso-Coello P, Schunemann HJ, Moberg J, Brignardello-Petersen R, Akl EA, Davoli M, et al. GRADE evidence to decision (EtD) frameworks: a systematic and transparent approach to making well informed healthcare choices. 1: Introduction. BMJ 2016;353:i2016.

38. Neumann I, Brignardello-Petersen R, Wiercioch W, Carrasco-Labra A, Cuello C, Akl E, et al. The GRADE evidence-to-decision framework: a report of its testing and application in 15 international guideline panels. Implement Sci 2016;11:93

39. Schunemann HJ. Guidelines 2.0: do no net harm-the future of practice guideline development in asthma and other diseases. Curr Allergy Asthma Rep 2011;11: 261-8. 
40. Bousquet J, Farrell J, Crooks G, Hellings P, Bel EH, Bewick M, et al. Scaling up strategies of the chronic respiratory disease programme of the European Innovation Partnership on Active and Healthy Ageing (Action Plan B3: Area 5). Clin Transl Allergy 2016;6:29.

41. Bousquet J, Schunemann HJ, Hellings PW, Arnavielhe S, Bachert C, Bedbrook A, et al. MACVIA clinical decision algorithm in adolescents and adults with allergic rhinitis. J Allergy Clin Immunol 2016;138:367-74.e2.
42. Bourret R, Bousquet J, Mercier J, Camuzat T, Bedbrook A, Demoly P, et al MASK-rhinitis, a single tool for integrated care pathways in allergic rhinitis. World Hosp Health Serv 2015;51:36-9.

43. Bousquet J, Schunemann HJ, Fonseca J, Samolinski B, Bachert C, Canonica GW, et al. MACVIA-ARIA Sentinel NetworK for allergic rhinitis (MASKrhinitis): the new generation guideline implementation. Allergy 2015;70: 1372-92. 